ENCYCLOPÉDIE Encyclopédie berbère

BERBERE

$30 \mid 2010$

30 | Maaziz - Matmata

\title{
Mariage (Noces en Kabylie) [témoignage]
}

M. T. Amrouche

\section{OpenEdition}

Journals

Édition électronique

URL : http://journals.openedition.org/encyclopedieberbere/471

DOI : 10.4000/encyclopedieberbere.471

ISSN : 2262-7197

\section{Éditeur}

Peeters Publishers

\section{Édition imprimée}

Date de publication : 29 décembre 2010

Pagination : 4615-4618

ISBN : 978-90-429-2367-6

ISSN : 1015-7344

\section{Référence électronique}

M. T. Amrouche, « Mariage (Noces en Kabylie) [témoignage] », Encyclopédie berbère [En ligne], 30 | 2010, document M41b, mis en ligne le 22 septembre 2020, consulté le 12 octobre 2020. URL : http:// journals.openedition.org/encyclopedieberbere/471 ; DOI : https://doi.org/10.4000/ encyclopedieberbere.471

Ce document a été généré automatiquement le 12 octobre 2020

(c) Tous droits réservés 


\title{
Mariage (Noces en Kabylie) [témoignage]
}

\author{
M. T. Amrouche
}

1 [D'après le récit fait avant 1939 par Fadhma Ait Mansour à sa fille Marguerite Taos Amrouche]

2 Il est des noces, en Kabylie, qui se célèbrent modestement et comme dans l'intimité, mais il en est aussi qui se célèbrent avec faste et qui donnent lieu à des réjouissances qui durent sinon sept jours et sept nuits, comme il est dit dans les légendes, du moins trois bons jours.

3 C'est l'été que l'on choisit de préférence. Déjà, dans la maison du garçon, on a trié le blé de la noce : deux grands sacs. Des parentes, des voisines sont venues : elles ont touché à ce blé avec bonheur, avec respect.

4 A cette occasion, des chants de joie ont éclaté et les petites filles ont dansé de tout leur cœur. Le blé a été changé en semoule. Les mêmes femmes se feront un honneur de venir rouler le couscous des noces.

5 La veille du mariage, c'est dans la maison de la jeune fille que la fête bat son plein. Les parents du garçon s'y rendent, précédés d'un ou deux agneaux sur pied et accompagnés de chanteurs ambulants accourus à leur demande de la plaine (Ideballen: ceux qui jouent du tambour d'épaule, et Isihliwen: « ceux qui viennent du Sahel, de la plaine »), pour conférer aux épousailles tout leur éclat.

6 C'est le premier soir des réjouissances, le soir dit de la «Veille ». Un grand repas est servi aux parents du fiancé ainsi qu'aux musiciens. Après le dîner, la troupe donne son premier concert qui dure toute la nuit. Des chants très savants et riches en vocalises montent, que seuls les maîtres du style asihel peuvent exécuter, des chants d'amour admirables qui ont enthousiasmé diverses contrées et sont devenus célèbres. Leur succèdent des airs de danse obsédants et délicieux. Les tambours et les tambourins vibrent. Les ghaïtas et les flûtes chantent, la poudre parle, des coups de feu et des youyou portent la joie à son plus haut sommet, tandis que les hommes et les femmes se jettent dans la danse et que jeunes et vieilles jambes obéissent aux rythmes. C'est la 
danse du foulard, pour les femmes, si noble et si chaste. Et la danse du bâton pour les hommes qui jouent avec les pans de leur burnous en exécutant une chorégraphie hiératique, éminemment virile.

7 La fiancée ne participe pas directement à la fête. Tenue à l'écart, dans une pièce, elle est toute aux préparatifs de sa toilette, mais les rires, les cris d'allégresse parviennent jusqu'à elle. Ses cheveux sont déjà teints au henné. Restent ses mains et ses pieds dont s'occupent de vieilles femmes expertes en l'art d'appliquer le henné. Et c'est le chant incantatoire du henné qui s'élève :

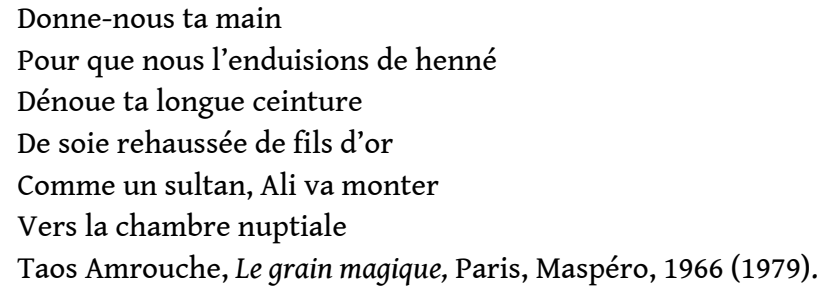

Dans la maison du fiancé, le spectacle est différent. Des femmes, à la faible lumière des lampes à huile, roulent le couscous des noces. Elles en roulent d'étonnantes quantités. En attendant d'être cuit à la vapeur, le grain est étalé sur des draps blancs. Dès l'aube, elles allumeront de grands feux de bois. Tandis qu'elles s'activent, les femmes chantent : elles lancent l'antique invitation à la joie qui se termine par des you-you :

\begin{tabular}{|l|l|}
\hline O toi de qui j'ai partagé la joie & a win umi ferḥer \\
\hline Viens te réjouir avec moi & yas-d yerr-iyi \\
\hline Rends-moi la joie que je t'ai donnée & \\
\hline Depuis trop longtemps nous étions & xịellah ayagi deg umalu ay nella \\
\hline sur le versant d'ombre & \\
\hline Mais voici que l'astre vient de naître & ilul-d waggur \\
\hline Déjà se répand sa lumière & tcerq-d tziri \\
\hline
\end{tabular}

Jean Amrouche, Chants berbères de Kabylie, Tunis, Monomotapa, 1939.

C'est le matin des noces. L'animation est intense dans les deux maisons. Des agneaux ont été sacrifiés. Escortés par les parents du garçon, les chanteurs ambulants quittent la maison de la jeune fille pour s'en revenir chez eux où les femmes leur ont préparé du thé, du café, des galettes de semoule friables comme des cacahuètes et des brochettes de foie et de cœur d'agneau. Les musiciens sont copieusement servis, tout le monde déjeune dans la joie et les femmes retournent à leurs occupations. Elles préparent le festin, découpent la viande, mettent sur le feu de grandes marmites, épluchent de pleines corbeilles d'oignons qu'elles mettent à mariner dans l'huile d'olive et saupoudrent abondamment de ce poivre rouge à peine piquant (ifelfel acbbas) qui donnera à la sauce sa belle couleur vermeille et toute sa saveur. Des coups de feu retentissent, accueillis par des cris de joie. 
10 Dans la maison de la jeune fille l'on s'occupe à préparer aussi un festin, mais plus particulièrement de la toilette de la jeune épousée. Celle-ci désigne pour l'aider à se baigner et à laver sa chevelure, la jeune femme la plus belle, la plus heureuse en ménage et la plus comblée. Et puis la mariée se remet entre les mains des femmes qui sauront la parer avec goût. Elle offre docilement son visage aux fards et ses cheveux au peigne. Sa parure est là, choisie avec soin. A quoi distingue-t-on la jeune épousée des autres adolescentes habillées, elles aussi, de leurs plus beaux atours? [...] A ses mains et à ses pieds teints complètement au henné, au collier sombre fleurant l'ambre gris et le clou de girofle qu'elle seule a le droit de porter, à sa chevelure éparse dans le dos, au foulard à larges tranches dorées qui lui couvre la tête et à la gaze pointillée d'or que l'on dispose délicatement sur son front et ses épaules à la façon d'une mantille (lqessa: écharpe de gaze scintillante), enfin à ses amples gandouras sans ceinture aux vaporeuses manches de tulle particulièrement chatoyantes. On fait asseoir la mariée sur les couvertures et les tapis neufs et l'on tend une corde pour que soient exposées aux regards les pièces les plus remarquables du trousseau.

11 Dans les deux maisons en liesse, on a souci de nourrir tous les pauvres qui se présentent lesquels, sont réellement accueillis «comme les hôtes de Dieu» (inebgi n Rebbi) et on envoie du couscous aux malades et à tous ceux qui ne peuvent accourir.

C'est de la maison du garçon que part le cortège, car c'est là que se sont donnés rendezvous tous ceux qui vont à la recherche de la jeune épousée, les parents des époux, les jeunes gens, les adolescentes et fillettes qui constituent le cortège. Il faut savoir en effet qu'au début de l'après-midi, la mariée s'est discrètement éloignée de chez elle pour aller se cacher dans une maison amie, comme le demande la coutume. Deux ou trois femmes l'ont escortée, chargées des plus belles pièces du trousseau. En tête du cortège, une mule douce au poil brillant. Autour de l'encolure, elle a un foulard solidement noué. C'est par là que la conduira la mère de la jeune fille. Un tapis recouvre la selle. Les hommes défilent dans leurs belles draperies blanches, fusils sur l'épaule, et puis les femmes et les adolescentes, les musiciens ferment la marche. De rue en rue, ce sont des chants, des you-you, des battements de mains. Les enfants du voisinage grossissent le cortège.

13 La maison où s'est cachée la jeune épousée est découverte et la cour de terre battue est envahie. Les chanteurs ambulants donnent un petit concert. Hommes et femmes dansent. La mule est richement caparaçonnée. On la recouvre entièrement de foulards à longues franges, de draperies rehaussées de broderies et d'arabesques de fils d'argent et d'or, de cachemires, de tulles pailletés et de pièces de velours. On fait monter la mariée sur la mule, on jette sur sa tête et ses épaules de brillantes étoffes, des voiles, des châles de soie brochée. Sous ce déploiement de richesses, elle disparaît, elle étouffe; néanmoins, elle a soin de se tenir très droite et très digne sur sa mule, aussi parée qu'elle-même. Le cortège refait le chemin en sens inverse. Les femmes lancent à pleine voix l'Appel à la Joie, la grande aubade rituelle : "O toi de qui j'ai partagé la joie... ». La poudre parle haut dans le ciel. Les tambours vibrent. Tout le village est en liesse. Les rues tortueuses et poussiéreuses s'illuminent au passage des musiciens et de la mariée à qui l'on chante la marche nuptiale accordée au pas lent de la mule :

Viens, viens, viens

Ô Fatima, tu seras mieux

Avec nous

Viens, viens, viens

O Yamina 
Viens, viens, viens

Tu seras mieux parmi nous!

Taos Amrouche, Le grain magique, Paris, Maspéro, 1966 (rééd, 1979). avec son précieux fardeau. La jeune épousée descend. On la porte pour lui faire traverser le seuil de la maison de l'époux. Elle prend place dans la pièce d'apparat. Sa mère lui tient la main, lui enlève les voiles qui la recouvrent. La mule est dépouillée de ses parures. A nouveau on fait une exposition du trousseau. Le cheikh de la mosquée vient célébrer le mariage religieux, dire la "Fatiha", et puis un grand bal est ouvert dans la cour. La mariée, assise sur des tapis y assiste de loin dans une attitude à la fois gracieuse et hiératique. Elle sourit modérément, veille à ce que tous ses gestes soient mesurés. Sa mère, ses tantes sont autour d'elle. Jeunes filles et jeunes gens dansent. Les coups de feu et le roulement du tambour grisent jeunes et vieilles têtes. Avant le coucher du soleil, les musiciens s'interrompent. Le grand repas de noces est servi. Les vastes plats de bois sur leur haut pied qui ressemblent à des coupes (lmetred) se succèdent. Ils sont pleins de couscous et garnis de viande et de légumes. Parents des conjoints, amis, chanteurs et aèdes se restaurent, ainsi que les pauvres que l'on entoure d'égards. La mariée mange seule, du bout des lèvres, en se faisant prier. Bientôt la fête reprend, qui durera toute la nuit...

Le lendemain, quatre hommes sortent de la maison de la mariée, portant sur leurs épaules un énorme plat de bois plein de couscous : «le plat de la mariée». A travers le village, ils le transportent jusqu'à la maison de l'époux pour le déposer devant les chanteurs ambulants. Le cortège fait plusieurs fois le tour du marabout et s'en revient au milieu des chants et des coups de feu. Les musiciens sont payés et s'en retournent dans leur contrée. Les parentes éloignées gagnent leurs villages respectifs. Peu à peu le calme se fait.

Jusqu'ici la mariée ne porte point de ceinture et ses cheveux sont répandus sur ses épaules. Des femmes les lui tressent. Un garçonnet s'avance et lui présente une ceinture. Un agneau dit « de la ceinture » est sacrifié. Les sœurs, les tantes de la jeune épousée s'en retournent avec des présents comme le veut la coutume - foulards de soie, gandouras, pièces d'étoffes. Et quant à l'oncle maternel, il a droit à une somme équivalent au prix d'un jeune veau : «le veau de l'oncle ».

C'est ce soir-là que les jeunes époux seront face à face. A la tombée de la nuit, les garçons du village envahissent la cour de terre battue, s'arrêtent sur le seuil de la chambre nuptiale. Le marié sort et leur distribue de pleins tamis de friandises : lfal - des cacahuètes, des raisins secs, des dattes, des noix, des œufs durs, des figues, pour les disperser. Et il offre comme l'exige la coutume, un présent à sa jeune épouse.

Le septième jour, la jeune femme va rendre visite à ses parents et leur fait offrande d'un quartier de mouton. Le cycle des réjouissances est fermé qui ne se rouvrira qu'avec la naissance d'un garçon. C'est la vie de chaque jour qui reprend, avec ses obligations et ses peines plus nombreuses que ses joies. 
INDEX

Mots-clés : Chant, Ethnologie, Ethnographie, Kabylie, Mariage, Rite, Rituel 